\title{
The predictive role of morphological awareness and productive vocabulary knowledge in L2 postgraduate students' academic writing
}

\author{
Hani Qasem Mohammed Asaad a * (D), Ahmad Affendi Shabdin a \\ ${ }^{a}$ School of Languages, Civilisation and Philosophy, Universiti Utara Malaysia, Sintok, 06010, Malaysia \\ Received 2 December 2019 | Received in revised form10 July 2020 | Accepted 30 January 2021
}

\begin{abstract}
APA Citation:
Asaad, H. Q. M., \& Shabdin, A. A. (2021). The predictive role of morphological awareness and productive vocabulary knowledge in L2 postgraduate students' academic writing. Eurasian Journal of Applied Linguistics, 7(1), 24-44.

Doi: $\underline{\text { http://dx.doi.org/10.32601/ejal.911149 }}$
\end{abstract}

\begin{abstract}
Studies have found that morphology awareness could assist writers to increase productive vocabulary (e.g. Green et al., 2003; McCutchen \& Stull, 2015), reduce vocabulary errors (e.g. Karakas, 2012; Ririn, 2010), and produce complex sentence structures using various forms of words. Postgraduate students as second language users of English (L2) were found to experience lack of vocabulary and have difficulties in their academic writing. Researchers have been concentrating on examining the relationship of morphological awareness with vocabulary reading, reading comprehension, receptive vocabulary knowledge, and spelling; however, there is still a shortage of studies examining the relationship of morphological awareness with academic writing, particularly among L2 postgraduate students. Therefore, this study aims to examine the correlation of morphological awareness with academic writing and investigate the extent to which the dimensions of morphological awareness and productive vocabulary knowledge predict the success of postgraduate students' academic writing in an ESL context. The results showed that there was a significant correlation between morphological awareness and academic writing. The synthetic dimension of morphological awareness had a stronger contribution than the analytic dimension to the L2 postgraduate students' academic writing. The results also showed that learning and teaching morphology could bring benefits to L2 postgraduate students, allowing students to improve their productive writing skills and enabling them to produce texts and convey their ideas meaningfully.
\end{abstract}

(C) 2021 EJAL \& the Authors. Published by Eurasian Journal of Applied Linguistics (EJAL). This is an open-access article distributed under the terms and conditions of the Creative Commons Attribution license (CC BY-NC-ND) (http://creativecommons.org/licenses/by-nc-nd/4.0/).

Keywords: Academic writing; morphological awareness; productive vocabulary knowledge; second language postgraduate students

\section{Introduction}

\subsection{Background}

\footnotetext{
* Corresponding author.

E-mail address: hanialasbahi@gmail.com

http://dx.doi.org/10.32601/ejal.911149
} 
The writing skill is considered a way of converting and expressing a writer's ideas and thoughts into texts, and thus the writer needs to have plenty of words and choose specific words that suit his writing purpose. Second language learners at universities face difficulties in writing and expressing their ideas and thoughts because of their insufficient vocabulary (González, 2017).

For tertiary students, writing is considered to be rigorous, with different problems facing them in terms of grammar, vocabulary, and syntax (Singh, 2015). Writing a thesis is a demanding task, especially for second language (hereafter referred to as L2) students due to inadequate English proficiency (Paltridge, 2002; Paltridge \& Woodrow, 2012). Vocabulary is crucial in writing and plays an essential role in L2 writing skills and fluency. High-quality writing is likely to involve a greater variety of vocabulary, words of varying levels of frequency, and many complex phrases (McNamara, Crossley, \& McCarthy, 2009).

Academic writing is a very important skill for postgraduate students to master their English language and succeed in their disciplines (Al Badi, 2015; Asaad \& Shabdin, 2019a, 2019b). Moreover, it is characterized by morphologically complex words (Nagy \& Townsend, 2012). The vocabulary that students face varies from one level of study to another, as they can predict to encounter more complicated words continuously at different levels of study (Northey, 2013). Additionally, students need more morphologically complicated words at the postgraduate stage to express the students' complicated ideas; therefore, students need to increase the size of their vocabulary with different types of complexity by using strategies and tools. One suggested strategy is to be aware of the patterns of word structure (Stowe, 2019). Learners of English do not have to memorize separate words (Carlisle \& Fleming, 2003) (e.g. act, action, actor, and active) as long as they can recognize the pattern followed in these words.

Previous studies in the literature have focused on the extent to which morphological awareness is correlated with reading (e.g. Fracasso, Bangs, \& Binder, 2016; Gardiner, 2013; Green et al., 2003; Kieffer \& Lesaux, 2007; Kuo \& Anderson, 2006; Levesque, Kieffer, \& Deacon, 2017; McCutchen \& Logan, 2011; Singson, Mahony, \& Mann, 2000; Xue \& Jiang, 2017; Zhang, 2016). Other studies have explored the correlation between morphological awareness and vocabulary reading (e.g. Kirby et al., 2012; Li \& Chen, 2016), and receptive vocabulary (e.g. Akbulut, 2017; Haomin \& Bilü, 2017; Khodadoust, Aliasin, \& Khosravi, 2013; Kraut, 2015; Latifi, Kasmani, Talebi, \& Shirvani, 2012; Sparks \& Deacon, 2015; Sumarni, 2016; Tabatabaei \& Yakhabi, 2011; Varatharajoo, 2016; Yucel-Koc, 2015; Zhang \& Koda, 2012). The relationship between morphological awareness and learners' spelling skills has also been examined (e.g. Carlisle, 2016; Dornay, 2017; Kirk \& Gillon, 2009). However, the relationship between morphological awareness and academic writing remains unknown (Asaad \& Shabdin, 2019a).

The receptive knowledge of vocabulary is generally linked with and required for listening and reading, while the productive knowledge of vocabulary is linked with 
writing and speaking (Laufer \& Goldstein, 2004). Many previous studies have investigated the relationship between morphological awareness and receptive vocabulary knowledge. To the best of the researchers' knowledge, there is a lack of studies investigating the relationship between morphological awareness and productive vocabulary knowledge and the role of productive vocabulary knowledge in improving the L2 postgraduate students' academic writing. The present study aimed to fill the gap in the literature by investigating the dimensions of productive vocabulary knowledge and morphological awareness to determine which dimensions have significantly affected and contributed to improving L2 postgraduate students' academic writing.

\section{Literature review}

\subsection{Morphological awareness and writing}

During writing, a writer should be aware that language is a system, and that system can be thought out and manipulated to achieve his/her purposes based on the audience. The language used for children is different from the language used for academic writing, and even the language that children use with each other at school is different from the language they use with their families (Schleppegrell, 2012). This skill of being aware of manipulating the functional and structural characteristics of a language is called 'metalinguistic awareness.' Morphological awareness is a type of metalinguistic awareness and refers to the "conscious awareness of the morphemic structure of words and ability to reflect on and manipulate that structure" (Carlisle \& Feldman, 1995).

Morphological awareness allows students to improve their writing skills because it enables them to address the internal formation and real meaning of words and produce effective texts. Manipulating the internal structure of words, such as nominalization, could facilitate writing by generating fluent syntactic sentences that reduce working memory constraints during writing (McCutchen, 2000). One of the characteristics of high-quality writing is the inclusion of various syntactic patterns (Myhill, 2008). By modifying the form of a word, by transforming it from one part of speech to another, such as the verb create is transformed into the adjective creative, this would allow syntactic flexibility in writing (Wolter \& Green, 2013) and syntactic flexibility can be attributed to good writing (McCutchen \& Stull, 2015). Therefore, knowing the rules of morphology and derivation could help writers apply easy manipulation to word forms while revising the syntax of sentences in writing (McCutchen \& Stull, 2015).

L2 postgraduate students could use the derived forms of words to change words, which shows their morphological awareness to achieve more syntactic complexity and writing flexibility. This ability to use morphology knowledge is vital for successful text comprehension and proper grammar and spelling in writing (Green et al., 2003). One 
of the writing requirements is to control morphological forms productively in a language (McCutchen \& Stull, 2015).

There is a difference in the ability of writers to identify individual vocabulary and facilitate access to vocabulary, as high-profile writers are likely to be faster than those with struggling skills in vocabulary selection. According to Chenoweth and Hayes (2001), there is a relationship between fluent language generation processes and higher quality texts. Morphological awareness could help L2 writers increase their vocabulary. When the vocabulary of L2 writers expands, the writers' ability to select appropriate vocabulary to express their semantic intent will be enhanced (McCutchen \& Stull, 2015). Moreover, morphological awareness could also help L2 writers increase the fluency of retrieving vocabulary from memory while writing (Green et al., 2003).

The fluency of word retrieval is the skill that writers need to expand their vocabulary and select the appropriate vocabulary to convey the intended semantic meaning. By increasing the vocabulary of a writer, his/her ability to choose the proper word for the proper intent is consequently enhanced (McCutchen \& Stull, 2015). Advanced writing skills are important as an essential aspect of academic performance in higher education, and this importance is not limited to academic performance at universities but extends to writing performance in the field of work (Kellogg \& Raulerson, 2007).

Awareness of the morphological structure of words and their grammatical functions plays an important role in linking the degree of lexical knowledge to the ability of learners to construct sentence structures (Berninger, Nagy, \& Beers, 2011; Carlisle, 2016). Awareness of morphology could help writers build complex sentence structures by using various forms of words. Morphological awareness could also help writers manipulate written language more effectively to achieve their rhetorical aims. Choosing the right words and order to put them in can help writers communicate more clearly to their audiences.

\subsection{Academic writing}

Generally speaking, academic writing has been found to be problematic and not an easy skill to be fulfilled, especially for L2 learners. L2 learners face difficulties in their academic writing in terms of grammar and vocabulary. According to Goodwin, Lipsky, and Ahn (2012), there are three challenges in academic writing, related to vocabulary:

Plenty of words: according to Nagy and Anderson (1984), there are 200,000 distinct words in academic texts. The number of words needed for learners to understand academic texts varies from 20 to 30 words a day (Nagy \& Anderson, 1984). Being aware of morphology can be helpful as knowing meaningful units of words helps figure out the meaning of $60 \%$ of the words (Nagy \& Anderson, 1984). For instance, understanding the meaning of the word movement can be achieved by knowing its segments (its root move- and its suffix -ment). 
Difficult and complex academic vocabulary: another challenge that an L2 learner encounters in academic texts is the complexity and difficulty of academic words. The types of vocabulary that students face are mostly characterized by being complex morphologically (Nagy \& Anderson, 1984). These words are difficult due to their formality as they express technical, abstract, subtle ideas that cannot be examined in a natural, casual, social conversation. These words are morphologically complex and contain roots and affixes that are not likely to be known to many students who only know the complete words, such as contradiction, interpretation, and retrospectively (Goodwin et al., 2012). Being aware of morphology may help students with these complex words by knowing how to analyze and synthesize (decompose and compose) them (Goodwin \& Ahn, 2010, 2013).

Using sophisticated and complicated words in syntactically complicated structures: the third challenge in academic vocabulary is using these words in content-specific texts. The academic language is distinguished by abstractness and density; it is difficult to understand and rich in information (Nagy \& Townsend, 2012).

\subsubsection{Role of vocabulary knowledge in academic writing}

At the college level, a learner has a different goal, and that is to be successful academically and not just learning English for daily communications. The language used for academic writing is different from the language used for daily communication (Nagy \& Townsend, 2012). Nagy and Townsend (2012) described the features of the language used academically as the following:

1. Words are morphologically complex: the vocabulary contained in the academic language tends to be long with multiple parts, and this length feature in the academic vocabulary is due to the addition of affixes. Using derivations to change parts of speech from one to another is a typical feature of academic language (different $>$ differentiate, manipulate $>$ manipulation, write $>$ writer). Unlike inflections, the acquisition of derivations occurs relatively late.

2. Grammatical Metaphor: It refers to "a part of speech used with a meaning not prototypical of that part of speech." In other words, a grammatical structure is shifted or altered by another with maintaining the meaning (Halliday \& Martin, 1993). For example, He evaluates the student's progress $>$ His evaluation of the student's progress. One of the most significant characteristics of grammatical metaphor is 'Nominalization'. This term is used to describe the process of creating nouns from other parts of speech, such as converting an adjective or a verb to a noun and adding a suffix to it (e.g., smile> smiling, happy > happiness, depart > departure, imagine $>$ imagination).

3. Density of information and vocabulary. The vocabulary and the language used are dense; it is difficult to understand the meaning of the information provided in each unit of a text in addition to the density of the academic vocabulary as the ratio of the vocabulary to the text.

4. Abstractness of the academic vocabulary. In each subject, there are abstract words related to the subject itself. For instance, abstract words (subtraction, width, 
addition) are used in math, while abstract words, such as respiration and absorbent, are included in biology.

Abstract and dense academic vocabulary are possibly created by making changes to the vocabulary's syntactic and structural patterns, such as nominalization, in which some parts of speech change from one class to another. This change process in the parts of speech occurs typically by using derivations (Nagy \& Townsend, 2012).

Several aspects of vocabulary knowledge can be drawn upon by L2 learners to determine the vocabulary that should be used in their writing (Coxhead, 2012). Two aspects of vocabulary knowledge are required for effective writing: knowing plenty of words and having strong knowledge of these words (Brun-Mercer \& Zimmerman, 2015). It is necessary for L2 learners to be lexically rich in their academic writing and to be able to choose appropriate high-frequency and academic vocabulary (Laufer \& Nation, 1995). However, learners must have more low-frequency vocabulary as previous studies have shown an association between low-frequency vocabulary and strong L2 writing performance (e.g. Johnson, Acevedo, \& Mercado, 2016; Laufer \& Nation, 1995). Productive knowledge of vocabulary, especially knowledge of the words used academically, is demanded in writing. L2 learners need to know the words used in writing by being aware of their meanings, forms, and use (Nation, 2001).

Academic vocabulary plays an essential role in the student's academic success, as a lack of academic vocabulary knowledge is considered a hurdle for the student to perform successfully (Nagy \& Townsend, 2012). The more vocabulary a writer has, the better his writing skills become (Smith, 2003). Barcroft (2004) pointed out the importance of vocabulary for L2 learners to improve in such a way that the more the L2 learners acquire vocabulary, the better they become.

Although academic vocabulary is vital to academic success, its complexity and abstractness pose challenges for L2 learners. The challenges faced by L2 learners while learning academic vocabulary lie in the difficulty of comprehending and using them, as they are mostly of Graeco-Latin origin. These challenges are attributed to academic vocabulary characteristics: low in frequency, abstract, low of imagery, and opaque in their meanings (Corson, 1997). The size and use of vocabulary are indicators of academic writing quality. The assessment of the writing is based on the richness and use of vocabulary (Nation, 2001).

\subsection{Writing models}

By reviewing the theoretical writing models, predictions can be made regarding the significance of morphological awareness in writing. The models of writing have been developed and conceptualized differently by many scholars. For example, Juel, Griffith, and Gough (1986) conceptualized writing on two aspects: ideas and spelling. Meanwhile, writing was considered to consist of three dimensions: transcription, text generation, and revising (Hayes \& Flower, 1980; Hayes, 1996; Berninger, 2000; Berninger \& Amtmann, 2003). The model offered by Hayes and Flower (1980), due to its features, has become a model used in many modern studies (Asaad \& Shabdin, 
$2019 b)$. Each writing process has its own separate function. Ideas are organized and generated for the purposes set out in the planning process. The second writing process involves translating the ideas of a writer into a language written on a page. The last writing process involves reviewing and editing the written text. This model is shown in Figure 1.

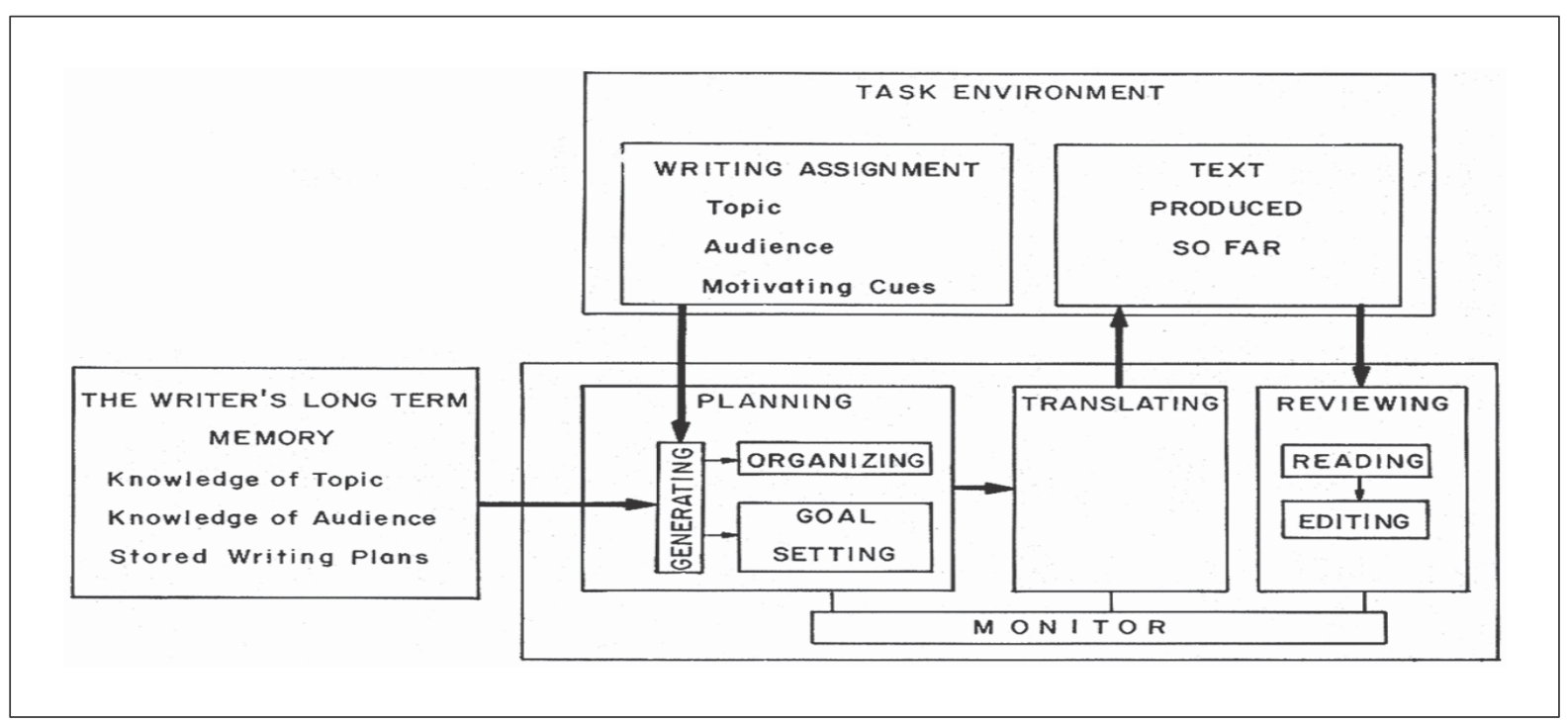

Figure 1. Writing model (Hayes \& Flower, 1980)

Working memory is related to the ability to write, and the organization of the three cognitive processes (planning, translation, and revision) is undoubtedly restricted by limited working memory (Alamargot \& Chanquoy, 2001). For most skilled adult writers, more resources of working memory are needed for planning and revising than for translating (Kellogg, 1987). Writers have a self-regulatory control over the compositions produced when they possess enough working memory resources. Thus, the more fluent and automatic their translating processes, the more working memory resources would be allotted for the planning and review processes-the process of translating effects substantially on the process of writing, and consequently, on the written text as well.

Therefore, morphological awareness could play a role in increasing vocabulary, which could improve writing and increase the resources of working memory to make a writer pay attention to higher levels, such as planning and revising.

\subsection{Related Studies}

Previous studies have focused on the relationship between morphological awareness and reading comprehension. For example, Shoeib (2017) conducted a study to explore the association of morphological awareness with reading comprehension among 35 EFL Saudi undergraduate English learners. The study also aimed to examine the learners' morphological awareness by measuring the two aspects of morphological awareness: the analytic aspect using the Morphological Identification 
Test and the synthetic aspect of morphological awareness using the Morphological Structure Awareness Test. The study results showed that the learners' ability to identify the morphemes of the given words in the Morphological Identification Test (Mean= 27. 11) was better than their ability to derive the different forms of the words given in the Morphological Structure Awareness Test (Mean= 14.66). It was also found that the learners' scores for the inflectional affixes (59.15\%) were better than their scores for the derivational affixes (46.33\%). The results of the study revealed that morphological awareness was correlated with reading comprehension. Intercorrelational analysis showed that both aspects of morphological awareness were correlated with reading comprehension $(r=0.869)$; however, the correlation between the analytic aspect of morphological awareness and reading comprehension $(r=0.871)$ was higher than the correlation of the synthetic aspect with reading comprehension $(\mathrm{r}$ $=0.841)$. The researcher emphasized the role of morphological awareness in enhancing the learners' reading comprehension and recommended that future research include morphological awareness training to enhance the learners' morphological awareness. He also recommended studying the relationship between morphological awareness and other language skills.

Deacon, Holliman, Dobson, and Harrison (2018) also aimed to explore the prediction of morphological awareness and prosodic sensitivity to reading comprehension, word reading and reading accuracy among native language children. Participants were given oral vocabulary and morphological awareness tests. The vocabulary was tested with a picture vocabulary test in which the participants chose the matched word based on the picture shown to them. Morphological awareness was examined by making the participants change the form of words orally to complete sentences. The results showed the significant contribution of morphological awareness to improved reading comprehension, word reading and text reading accuracy.

In similar studies, morphological awareness has been reported to be correlated with receptive vocabulary breadth. For instance, Sumarni (2016) studied the correlation between morphological awareness (measured by the Morphological Identification Test and the Morphological Structure Test) with receptive vocabulary breadth measured by the Vocabulary Levels Test. The researcher used the vocabulary levels test to test the participants' receptive vocabulary breadth. Unsurprisingly, the findings revealed a significant correlation between morphological awareness and vocabulary breadth. The findings also showed that the participants performed better in the morphological identification test more than in the morphological structure test. An insignificant correlation was also reported between vocabulary breadth and morphological structure test; however, the vocabulary breadth was significantly correlated with the result of the morphological identification test.

Akbulut (2017) examined the relationship between morphological awareness and vocabulary size among university preparatory class students in Turkey. Nation's Vocabulary Level Test was used to measure the learners' receptive vocabulary size. In order to test morphological awareness, the students were asked if they knew the meaning of some words given to them or not in part A. The second part of the 
morphological awareness test was to examine the students' abilities to identify the separate internal parts of the given words. The experimental group outperformed the control group in the vocabulary tests. The study concluded that morphological awareness was related to vocabulary size.

Additionally, Tabatabaei and Yakhabi (2011) investigated the association between morphological awareness and receptive vocabulary breadth among Iranian senior high school students. The researchers employed the vocabulary levels test for measuring vocabulary breadth, the morphological identification awareness test and the morphological structure awareness test to measure the participants' morphological awareness. The results showed that there was a relationship between morphological awareness and vocabulary breadth.

In regard to the relationship between morphological awareness and spelling, Green et al. (2003) aimed to explore the improvement of morphological markers and the effect of morphology on spelling and reading while writing. 247 students in the $3 \mathrm{rd}$ and 4th grades whose first language was English participated in Green et al. (2003)' study. Several tests were administered, including Gates-MacGinitie Reading Test, Reading Vocabulary Test, Reading Comprehension test, Spelling Test, and Orthographic Fluency Test. It was found that there was a significant outperformance of the fourth graders over the third graders in relation to the accuracy of inflections.

The findings reviewed in the previous studies supported the contribution of morphological awareness to reading comprehension, receptive vocabulary breadth, and spelling. However, there is a dearth of research investigating the role of morphological awareness and productive vocabulary knowledge in academic writing among L2 postgraduate students. In addition, it remains unclear which dimensions of morphological awareness and productive vocabulary knowledge best predict the academic writing performance of L2 postgraduate students. Based on the literature review and the addressed research gaps, three research questions are intended to be investigated.

The research questions of this study were:

1. Is morphological awareness correlated with academic writing among L2 postgraduate students?

2. Is productive vocabulary knowledge correlated with academic writing among L2 postgraduate students?

3. Which dimensions of morphological awareness and productive vocabulary knowledge best predict the academic writing performance of L2 postgraduate students?

\section{Method}

\subsection{Participants}


The cluster sampling design was the design used in this study. When the individual members of a population are impractical to be selected, and cluster becomes the unit of selection, cluster sampling design is used (Cohen, Manion, \& Morrison, 2007; Kothari, 2004). Two groups (two clusters) of L2 postgraduate students participated in the current study. A total of 30 L2 postgraduate students, who attended an intensive English course in a Malaysian university, participated in the study. The study included sixteen Arabic-speaking students (53.3\%), five Indonesian-speaking students (16.7\%), six Chinese-speaking students (20\%), and three Somali-speaking students (10\%). These participants were divided into seventeen male respondents (56.7\%), and thirteen female respondents (43.3\%). There were nineteen participants $(63.3 \%)$ in the master's program and eleven participants (36.7\%) in the PhD. program.

\subsection{Research instruments}

The instruments used in the analysis of this study are listed in detail in Table 1. The researcher used a series of tests (as described in detail in sections 3.2.1, 3.2.2, and 3.2.3) to provide the data required for analyzing the research questions, which would help achieve the study's objectives.

Table 1. Instruments used in the study

\begin{tabular}{ll}
\hline Variable & Test \\
\hline Morphological Awareness & Morphological Identification Test \\
& Morphological Structure Awareness Test \\
Productive Vocabulary Knowledge & Productive Vocabulary Level Test \\
Academic Writing & Academic Writing Test \\
\hline
\end{tabular}

\subsubsection{Measurements of morphological awareness}

The L2 postgraduate students' morphological awareness was measured by administering two tests. The analytic dimension of morphological awareness was tested by using the Morphological Identification Test. Students were required to break down the provided words into their smallest meaningful parts (morphemes). The test consisted of 24 test items. The test was adapted from Al Farsi (2008). The test was piloted and was reliable at .912.

The Morphological Structure Awareness test examined the synthetic dimension of morphological awareness; participants were required to synthesize morphemes and create a different form of a word and a new meaning. The test was adapted from Wilson-Fowler and Apel (2015). The test was piloted and found to be reliable at .834.

There were seven levels of affixes determined by Bauer and Nation (1993). Three levels of affixes were beyond the scope of this current study. According to Bauer and Nation (1993) classification, the first level was "Each form is a different word." This level was excluded from the current study as it contradicted the definition of vocabulary in the current study since vocabulary refers to a word form, including its derived forms (Laufer \& Nation, 1995). Therefore, the word and its derived forms are counted as one word. 
The second level of affixes includes all the inflectional suffixes, which was beyond the current study's scope because the present study focuses on derivational affixes. The seventh level was also excluded because of the difficulty of its affixes as the level includes classical roots and affixes. The current study included affixes from Level 3 to Level 6. Sample items can be seen in Table 2. It is worth mentioning that all the words used in the morphological awareness tests were academic.

Table 2. Sample items used in the morphological awareness tests

\begin{tabular}{ll}
\hline Level & Items \\
\hline Three & responsiveness, observable, painless \\
Four & fertility, odorous, regional \\
Five & contradictory, authorship, electrician \\
Six & artistic, productive, definition \\
\hline
\end{tabular}

Table 3. Bauer and Nation (1993)'s Levels of Affixes

\begin{tabular}{ll}
\hline Level No & Affixes \\
\hline Level One & Each word form is considered as a different word (no word family) \\
Level Two & $\begin{array}{l}\text { Regularly inflected words are part of the same family. The inflectional categories are - plural; } \\
\text { third person singular present tense; past tense; past participle; -ing; comparative; superlative; } \\
\text { possessive. }\end{array}$ \\
& $\begin{array}{l}\text { The most regular and frequent derivational affixes : -able, -ish, -er, -ly, -less, -ness, -y, -th, un-, } \\
\text { non- }\end{array}$ \\
& Regular and frequent affixes: -al, -ation, -ize, -ess, -ful, -ous, -ism, -ist, -ity, -ment, in-, im-, ir \\
Level Four & $\begin{array}{l}\text { Fifty Regular but Infrequent affixes: e.g. -age, -an, -ance, -ant, -ary, -dom (kingdom), -ence, -ese, - } \\
\text { hood (childhood), -ory, -ship, etc. }\end{array}$ \\
Level Five & $\begin{array}{l}\text { Frequent but irregular affixes: -able (permeable), -ee, -ic, -ify, -ion, -ist, -ition, -ive (productive), - } \\
\text { th, -y, pre-, re- } \\
\text { Classical (Greek and Latin) roots and affixes, e.g., astronaut, bibliography,-ure, de-, sub-, com-, ab- } \\
\text { Level Seven }\end{array}$ \\
&, etc.
\end{tabular}

\subsubsection{Vocabulary tests}

The productive vocabulary levels test, adapted from Laufer and Nation (1999), was administered. The test examines the productive vocabulary breadth in five levels of vocabulary frequency: $2 \mathrm{k}$ (i.e. 2000 frequency level), 3k, 5k, 10k, and the University Word List frequency level (academic vocabulary). The test was found to be reliable at .931; however, the pilot study revealed that the last vocabulary frequency level (10000) was difficult for the students to answer as most of the items in this level were wrong or left with no attempt to answer them. Therefore, the researchers excluded this level and tested the other four vocabulary levels.

\subsubsection{Academic writing test}

The participants were asked in this test to write about one of the two academic writing topics provided to them: "In some countries, the average weight of people is increasing, and their levels of health and fitness are decreasing. What do you think are the causes of these problems and what measures could be taken to solve them?" 
and "In many countries, the amount of crime is increasing. What do you think are the main causes of crime? How can we deal with those causes?"

Two independent raters with more than three years of experience teaching university-level writing rated the participants' writing in the current study. The IELTS rubric was used to evaluate the academic writing of L2 postgraduate students, based on four rubrics (Task Achievement, Coherence and Cohesion, lexical resource, and Grammatical Range and Accuracy) because it provides a comprehensive assessment of the learners' vocabulary knowledge and the type of vocabulary used in their writing. In addition, IELTS shows many aspects of vocabulary used in the students' writing in terms of the range of vocabulary, the sophistication of vocabulary usage, choice of words, and the lexical frequency used in their writings. The IELTS rubric uses a holistic scoring scale ranging from 1 to 9 . A Pearson product-moment correlation demonstrated good inter-rater reliability of .83 $(P<.001)$. Then the score of each student rated by rater 1 and 2 was calculated for means using the formula:

Means $=$

the score of rater $1+$ the score of rater 2

\subsection{Procedure}

After obtaining permission from the institution in which the study was conducted, the respondents were provided with a consent form confirming voluntary participation in the study. Two tests of morphological awareness and a productive vocabulary levels test were administered to the study respondents, who were also asked to write about one of the topics they were given in the academic writing test. Before the main study tests were administered, the two adapted morphological awareness tests were piloted and tested. The pilot test results showed that the morphological identification test was reliable at .912, the morphological structure awareness test was reliable at .834, and the productive vocabulary levels test was reliable at .931 in Cronbach's alpha test.

\subsection{Data analysis}

The data of the study were analyzed using SPSS (version 25). Descriptive statistics on the study variables are provided in Table 4. The Pearson coefficient test was carried out to examine the correlation between morphological awareness and L2 postgraduate students' academic writing. Table 4 presents the statistical description of the variables, including their dimensions, for the present study. (e.g. mean, skewness, and kurtosis values). A regression analysis test was conducted in this study in which the correlation between variables was evaluated and described. 
Table 4. Descriptive statistics

\begin{tabular}{lllllllll}
\hline & & & & \multicolumn{2}{l}{ Skewness } & \multicolumn{2}{l}{ Kurtosis } \\
\cline { 6 - 9 } & $\mathrm{N}$ & Mean & Std. Deviation & Statistic & Std. Error & Statistic & \multicolumn{2}{l}{$\begin{array}{l}\text { Std. } \\
\text { Error }\end{array}$} \\
\hline Analytic Morphological Awareness & 30 & 28.50 & 8.529 & -.138 & .427 & -.240 & .833 \\
Synthetic Morphological Awareness & 30 & 6.03 & 3.801 & .364 & .427 & -.514 & .833 \\
Morphological Awareness & 30 & 34.53 & 11.066 & -.247 & .427 & -.195 & .833 \\
Vocabulary Breadth & 30 & 4.17 & 3.752 & 1.124 & .427 & .898 & .833 \\
vocabulary Depth & 28 & 10.14 & 3.535 & .063 & .441 & -.555 & .858 \\
vocabulary Use & 28 & 9.64 & 2.281 & 1.042 & .441 & .040 & .858 \\
Vocabulary Knowledge & 28 & 24.07 & 5.868 & .531 & .441 & -.002 & .858 \\
Academic Writing & 28 & 4.36 & 1.393 & .362 & .441 & -.955 & .858 \\
\hline
\end{tabular}

\section{Results}

\subsection{Research Question One and Two}

The study aimed to investigate the correlations between morphological awareness and productive vocabulary knowledge on the one hand and L2 postgraduate students' academic writing, on the other hand. To test and describe the correlations between morphological awareness and productive vocabulary knowledge (i.e. the independent variables) and academic writing (i.e. the dependent variable), a correlation analysis test was used (Creswell, 2012; Pallant, 2005).

Table 5 describes the Pearson coefficient test results for the relationships between morphological awareness and productive vocabulary knowledge and academic writing. The table shows that morphological awareness was significantly correlated with academic writing at the 0.01 significance level $(r=.562, P=.002)$. The relationship between productive vocabulary knowledge and academic writing was significant at the 0.05 significance level $(r=.368, P=.027)$. Regarding the direction of the correlations between the independent variables and the dependent variable, Table 5 also shows that the correlations were significantly positive, which implies that when the scores of morphological awareness and productive vocabulary knowledge increase, the scores of academic writing increase. 
Table 5. Result of the Pearson coefficient test for the relationship of morphological awareness and productive vocabulary knowledge with academic writing

\begin{tabular}{lllll}
\hline & & $\begin{array}{l}\text { Morphological } \\
\text { Awareness }\end{array}$ & Academic Writing Test & $\begin{array}{l}\text { Productive Vocabulary } \\
\text { Knowledge }\end{array}$ \\
\hline Morphological Awareness & Pearson Correlation & 1 & $.562^{* *}$ & $.514^{* *}$ \\
& Sig. (2-tailed) & & .002 & .003 \\
Academic Writing & $\mathrm{N}$ & 30 & 28 & 28 \\
& Pearson Correlation & $.562^{* *}$ & 1 & $.368^{*}$ \\
& Sig. (2-tailed) & .002 & & .027 \\
Productive Vocabulary & $\mathrm{N}$ & 28 & 28 & 28 \\
Knowledge & Pearson Correlation & $.514^{* *}$ & $368^{*}$ & 1 \\
& Sig. (2-tailed) & .003 & .027 & \\
& $\mathrm{~N}$ & 28 & 28 & 28 \\
\hline
\end{tabular}

**. Correlation is significant at the 0.01 level (2-tailed).

*. Correlation is significant at the 0.05 level (2-tailed).

\subsubsection{Research Question Three}

The aim of this research question was to determine the most significant predictor of academic writing and the extent to which the dimensions of morphological awareness and productive vocabulary knowledge would contribute to the academic writing of L2 postgraduate students. Table 6 describes the regression analysis results in the study in which the values of ANOVA, the prediction, and the coefficient for the five independent variables on academic writing were reported.

Table 6. Result of regression predicting academic writing

\begin{tabular}{|c|c|c|c|c|c|c|c|c|c|}
\hline & \multirow[t]{2}{*}{$R$} & \multirow[t]{2}{*}{$R^{2}$} & \multirow[t]{2}{*}{ Adjusted $R 2 F$} & \multirow[t]{2}{*}{ B } & \multirow[t]{2}{*}{$\mathrm{t}$} & \multirow[t]{2}{*}{$P$} & \multicolumn{3}{|c|}{ Correlation } \\
\hline & & & & & & & $\bar{r}$ & Partial & Part \\
\hline Academic Writing & .878 & .772 & 14.873 & & & $.000^{* *}$ & & & \\
\hline $\begin{array}{l}\text { Analytic Morphological } \\
\text { Awareness }\end{array}$ & & & & -.046 & -.384 & .705 & 0.406 & -0.082 & -0.039 \\
\hline $\begin{array}{l}\text { Synthetic Morphological } \\
\text { Awareness }\end{array}$ & & & & .626 & 3.324 & $.003^{*}$ & 0.690 & 0.578 & 0.339 \\
\hline Vocabulary Breadth & & & & -.417 & -2.603 & $.016^{*}$ & 0.365 & -0.485 & -0.265 \\
\hline Vocabulary Depth & & & & -.115 & -1.103 & .282 & -0.296 & -0.229 & -0.112 \\
\hline Vocabulary Use & & & & .596 & 4.246 & $.000 * *$ & 0.799 & 0.671 & 0.432 \\
\hline
\end{tabular}

Table 6 demonstrates that the $F$ value of the model was significant at the 0.001 level $(F=14.873),(P<.001)]$. The $\mathrm{R}$-square value was also reported in the table, which shows the extent of variation the independent variables, namely analytic morphological awareness, synthetic morphological awareness, vocabulary depth, vocabulary breadth, and vocabulary use, explain the dependent variable. Thus, the $\mathrm{R}^{2}$ value of .772 indicates that the five predictors jointly explained $77.2 \%$ of the variance in academic writing. 
Regarding which dimensions of morphological awareness and productive vocabulary knowledge were the most significant predictors and contributors to academic writing, Table 6 shows that vocabulary use $(\beta=.596, P=.000)$, synthetic morphological awareness $(\beta=.626, P=.003)$, and vocabulary breadth $(\beta=. .417, P=.016)$ had the most significant contribution to academic writing. Squaring the part coefficient value of $(0.432,0.339,-0.265)$ means that vocabulary use, synthetic morphological awareness, and vocabulary breadth accounted for $18.66 \%, 11.49 \%$, and $7.02 \%$ of the variance of academic writing score. Therefore, the result of the regression shown in Table 6 and the above discussion reveals that the highest unique prediction of good academic writing was vocabulary use followed by synthetic morphological awareness and vocabulary breadth $(18.66 \%, 11.49 \%$, and $7.02 \%)$. However, the regression also showed that the analytic morphological awareness and vocabulary depth did not significantly predict academic writing.

\section{Discussion \& Conclusion}

The current study aimed to examine the relationship between morphological awareness and productive vocabulary knowledge and L2 postgraduate students' academic writing. It also aimed to determine which dimensions of morphological awareness and productive vocabulary knowledge significantly contributed to and predicted the students' academic writing performance.

The study's findings revealed that morphological awareness and productive vocabulary knowledge were significantly correlated with academic writing. The existence of a significant correlation in the present study between morphological awareness and productive vocabulary knowledge and academic writing was expected based on the results of prior studies. Morphological awareness was found to be correlated with different language skills, such as reading (e.g. Apel \& Diehm, 2014; Choi, 2015; Deacon et al., 2018; Shoeib, 2017), spelling (e.g. Fracasso et al., 2016; McCutchen \& Stull, 2015; Green et al., 2003), and vocabulary (e.g. Akbulut, 2017; Levesque et al., 2017; Li \& Chen, 2016; Sparks \& Deacon, 2015; Sumarni, 2016; Tabatabaei and Yakhabi, 2011; Xue \& Jiang, 2017; Zhang, 2016).

For example, Shoeib (2017) investigated the relationship between morphological awareness and reading comprehension among 35 Saudi undergraduate learners of English. The researcher emphasized the contribution of morphological awareness in improving the learners' reading comprehension. This finding was also supported by Deacon, Holliman, Dobson, and Harrison (2018), who showed that morphological awareness was significantly predictive of reading comprehension, word reading, and text reading accuracy. Morphological awareness was found to be correlated with receptive vocabulary knowledge. For instance, Akbulut (2017), Tabatabaei and Yakhabi (2011), Sumarni (2016), and Sparks and Deacon (2015) investigated the relationship between morphological awareness and receptive vocabulary breadth. The results showed that morphological awareness was significantly related to receptive vocabulary breadth. 
With regards to the relationship between morphological awareness and the spelling skill in writing, the findings of several researchers, such as Carlisle (1996) and Green et al. (2003), have revealed the contribution of morphological awareness to spelling accuracy and development. Likewise, Fracasso et al. (2016) examined to what extent morphological awareness and phonological decoding predicted spelling, vocabulary, and reading comprehension among adult primary education populations. The phonological decoding task, morphological structure test, suffix choice task, and spelling task were used to measure the variables. The findings of the study showed that phonological decoding was predicting reading comprehension, listening comprehension, and spelling ability, whereas morphological awareness was only predicting vocabulary, spelling, and listening comprehension. Therefore, this study has contributed to revealing the relationship between morphological awareness and two other language skills, i.e. academic writing and productive vocabulary knowledge.

The study has also revealed that productive vocabulary knowledge was significantly correlated with the scores of academic writing. In other words, the more productive vocabulary knowledge L2 postgraduate students have, the more successful they are in academic writing. This result was in line with the results of previous studies conducted by Johnson et al. (2016) and Karakoç and Köse (2017) emphasizing the significant contribution of productive vocabulary knowledge to writing.

The results of the regression test, as shown in Table 6 , revealed that the correlation of the synthetic dimension of morphological awareness was higher than the correlation of the analytic dimension with academic writing. In other words, the synthetic dimension of morphological awareness was a stronger predictor than the analytic dimension. This finding was inconsistent with the findings of Sumarni (2016), who found that there was an insignificant relationship between synthetic morphological awareness and receptive vocabulary; however, the relationship between the participants' analytic morphological awareness and their receptive vocabulary was significant. The possible interpretation of this finding was that the participants in the synthetic morphological awareness were required to produce different forms of words, while they merely had to recognize the morphemes of words in the analytic morphological awareness. Since academic writing is a productive language skill that involves learners' ability to produce morphologically and grammatically appropriate words, synthetic morphological awareness seems to be more related to academic writing than analytic morphological awareness.

The regression results emphasized the contribution of the synthetic dimension of morphological awareness as one of the most significant predictors of the academic writing of L2 postgraduate students. The regression results demonstrated that the five predictors (analytic morphological awareness, synthetic morphological awareness, vocabulary breadth, vocabulary depth, and vocabulary use) included in the model jointly accounted for $77.2 \%$ of the variance of the scores of academic writing. Being aware of the morphological rules, the learners of English gain knowledge about morphemes and the internal structure of English words, and consequently, they have the knowledge they need to manipulate the word-formation rules of these words. 
The findings revealed that learners who gained more awareness of morphology performed better in their academic writing. In other words, the more L2 postgraduate students were aware of morphemes and how to identify and combine words based on their morphological awareness, the better their academic writing performance would be. From a theoretical perspective, the present study is eligible to be used as a basis for future research investigation about the correlation between morphological awareness and academic writing. The Literature review of the current study revealed a severe dearth of research in this regard. The focus of prior studies was on investigating the correlation between morphological awareness and different language skills (i.e. word reading, reading comprehension, receptive vocabulary knowledge, and spelling). Therefore, the current study reduced this gap by examining the relationship between morphological awareness and academic writing.

The current study's implications can be indicated concerning its possible usefulness and significance as a guideline for English language teaching and learning, material development, curriculum designing, and future research. The present study may provide an insight to guide both the learners and teachers of English by shedding light on the significance of being aware of morphology and what benefits they both can gain in improving the performance of the students' academic writing, and suggesting a strategy that may enable L2 postgraduate students to enhance their academic writing. Morphological awareness is a possible way of independent learning in which the L2 postgraduate students would be able to use and strengthen their academic writing performance. The study may also draw the teachers' attention to the importance of teaching morphology and the different forms of words and encourage their students to employ different morphological forms of words in their writings. Implications of the current study may be represented in making material designers aware of the importance of including more morphology lessons and alloting more word formation exercises in the English teaching textbooks.

\section{The Research and Publication Ethics Statement}

Data were collected after getting the consent of the participants. No ethical considerations were violated in this study.

\section{The Conflict of Interest Statement}

In line with the statement of Committee on Publication Ethics (COPE), we hereby declare that we had no conflicting interests regarding any parties of this study.

\section{References}

Akbulut, F. D. (2017). Effects of morphological awareness on second language vocabulary knowledge. Journal of Language and Linguistic Studies, 13(1), 10-26.

Al Badi, I. A. H. (2015). Academic writing difficulties of ESL learners. Paper presented at the WES International Academic Conference Proceedings.

Al Farsi, B. (2008). Morphological awareness and its relationship to vocabulary knowledge and morphological complexity among Omani EFL University students. The University of Queensland. 
Alamargot, D., \& Chanquoy, L. (2001). Through the models of writing: With commentaries by Ronald T. Kellogg \& John R. Hayes (Vol. 9): Springer Science \& Business Media.

Asaad, H. Q. M., \& Shabdin, A. A. (2019a). Conceptualization of morphological awareness and productive vocabulary knowledge with academic writing. International Journal of Academic Research in Progressive Education and Development, 8(1), 1-11. doi: DOI: 10.6007/IJARPED/v8-i1/5271

Asaad, H. Q. M., \& Shabdin, A. A. (2019b). Importance of morphological awareness to academic writing among second language postgraduate students. European Journal of English Language Teaching, 4(3), 156-167. doi: 10.5281/zenodo.1307432

Barcroft, J. (2004). Effects of sentence writing in second language lexical acquisition. Second Language Research, 20(4), 303-334.

Berninger, V. W., Nagy, W., \& Beers, S. (2011). Child writers' construction and reconstruction of single sentences and construction of multi-sentence texts: Contributions of syntax and transcription to translation. Reading and Writing, 24(2), 151-182. doi: DOI: 10.1007/s11145-010-9262-y

Brun-Mercer, N., \& Zimmerman, C. B. (2015). Fostering academic vocabulary use in writing. CATESOL Journal, 27(1), 131-148.

Carlisle, A. A. (2016). The effect of a morphological awareness intervention on early writing outcomes. University of Missouri-Columbia.

Carlisle, J. F., \& Feldman, L. (1995). Morphological awareness and early reading achievement. In Morphological aspects of language processing (pp. 189-209).

Carlisle, J. F., \& Fleming, J. (2003). Lexical processing of morphologically complex words in the elementary years. Scientific Studies of Reading, 7(3), 239-253. doi: 10.1207/S1532799XSSR0703_3

Chenoweth, N. A., \& Hayes, J. R. (2001). Fluency in writing generating text in L1 and L2. Written Communication, 18(1), 80-98. doi: https://doi.org/10.1177/0741088301018001004

Cohen, L., Manion, L., \& Morrison, K. (2007). Research methods in education. London: Routledge.

Corson, D. (1997). The learning and use of academic English words. Language Learning, 47(4), 671-718.

Coxhead, A. (2012). Academic vocabulary, writing and English for academic purposes: Perspectives from second language learners. RELC Journal, 43(1), 137-145. doi: https://doi.org/10.1177/0033688212439323

Creswell, J. W. (2012). Educational research: Planning, conducting, and evaluating quantitative and qualitative research (4th ed.): Pearson Education, Inc.

Deacon, S. H., Holliman, A. J., Dobson, G. J., \& Harrison, E. C. J. (2018). Assessing direct contributions of morphological awareness and prosodic sensitivity to children's word reading and reading comprehension. Scientific Studies of Reading, 22(6), 527-534. doi: https://doi.org/10.1080/10888438.2018.1483376

Dornay, M. A. (2017). The effects of morpheme and prosody instruction on middle school spelling. Seattle Pacific University.

Fracasso, L. E., Bangs, K., \& Binder, K. S. (2016). The contributions of phonological and morphological awareness to literacy skills in the adult basic education population. Journal of Learning Disabilities, 49(2), 140-151. doi: https://doi.org/10.1177/0022219414538513

Gardiner, I. R. (2013). Putting two and two together. Journal of Adolescent \& Adult Literacy $56(7), 541-553$.

González, M. C. (2017). The contribution of lexical diversity to college-level writing. TESOL Journal, 8(4), 899-919. 
Goodwin, A., Lipsky, M., \& Ahn, S. (2012). Word detectives: Using units of meaning to support literacy. The Reading Teacher, 65(7), 461-470. doi: DOI: 10.1002/TRTR.01069

Goodwin, A. P., \& Ahn, S. (2010). A meta-analysis of morphological interventions: Effects on literacy achievement of children with literacy difficulties. Annals of Dyslexia, 60(2), 183208. doi: doi: 10.1007/s11881-010-0041-x

Goodwin, A. P., \& Ahn, S. (2013). A meta-analysis of morphological interventions in English: Effects on literacy outcomes for school-age children. Scientific Studies of Reading, 17(4), 257-285. doi: DOI: 10.1080/10888438.2012.689791

Green, L., McCutchen, D., Schwiebert, C., Quinlan, T., Eva-Wood, A., \& Juelis, J. (2003). Morphological development in children's writing. Journal of Educational Psychology, 95(4), 752-761. doi: https://doi.org/10.1037/0022-0663.95.4.752

Halliday, M. A. K., \& Martin, J. R. (1993). Writing science: Literacy and discursive power: Taylor \& Francis.

Haomin, Z., \& Bilü, Z. (2017). Multi-faceted morphological awareness and vocabulary knowledge in English as a second language learners: A multivariate analysis. Chinese Journal of Applied Linguistics, 40(1), 42-55. doi: 10.1515/cjal-2017-0003

Hayes, J. R., \& Flower, L. (1980). Identifying the organization of writing processes. In L. Gregg \& E. R. Steinberg (Eds.), Cognitive processes in writing (pp. 3-30). Hillsdale, NJ: Lawrence Erlbaum Associates.

Johnson, M. D., Acevedo, A., \& Mercado, L. (2016). Vocabulary knowledge and vocabulary use in second language writing. TESOL Journal, 7(3), 700-715. doi: DOI: 10.1002/tesj.238

Juel, C., Griffith, P. L., \& Gough, P. B. (1986). Acquisition of literacy: A longitudinal study of children in first and second grade. Journal of Educational Psychology, 78(4), 243-255. doi: https://doi.org/10.1037/0022-0663.78.4.243

Karakas, A. (2012). Analysis of Turkish students' morphological and syntactical errors in writing.

Karakoç, D., \& Köse, G. D. (2017). The impact of vocabulary knowledge on reading, writing and proficiency scores of EFL learners. Journal of Language and Linguistic Studies, 13(1), 352-378.

Kellogg, R. T. (1987). Writing performance: Effects of cognitive strategies. Written Communication, 4(3), 269-298.

Kellogg, R. T., \& Raulerson, B. A. (2007). Improving the writing skills of college students. Psychonomic Bulletin \& Review, 14(2), 237-242.

Khodadoust, E., Aliasin, S., \& Khosravi, R. (2013). The relationship between morphological awareness and receptive vocabulary knowledge of Iranian EFL learners International Journal of Educational Research and Technology 4(1), 60-67.

Kieffer, M. J., \& Lesaux, N. K. (2007). Breaking down words to build meaning: Morphology, vocabulary, and reading comprehension in the urban classroom. The Reading Teacher, 61(2), 134-144. doi: https://doi.org/10.1598/RT.61.2.3

Kirby, J. R., Deacon, S. H., Bowers, P. N., Izenberg, L., Wade-Woolley, L., \& Parrila, R. (2012). Children's morphological awareness and reading ability. Reading and Writing, 25(2), 389410. doi: $10.1007 / \mathrm{s} 11145-010-9276-5$

Kirk, C., \& Gillon, G. T. (2009). Integrated morphological awareness intervention as a tool for improving literacy. Language, Speech, and Hearing Services in Schools, 40(3), 341-351. doi: 10.1044/0161-1461(2008/08-0009)

Kothari, C. R. (2004). Research methodology: Methods and techniques: New Age International.

Kraut, R. (2015). The relationship between morphological awareness and morphological decomposition among English language learners. Reading and Writing, 28(6), 873-890. doi: $10.1007 / \mathrm{s} 11145-015-9553-4$ 
Kuo, L.-j., \& Anderson, R. C. (2006). Morphological awareness and learning to read: A crosslanguage perspective. Educational Psychologist, 41(3), 161-180. doi: https://doi.org/10.1207/s15326985ep4103 3

Latifi, Z., Kasmani, M. B., Talebi, S. H., \& Shirvani, K. E. (2012). Morphological awareness and its relationship to vocabulary size and morphological complexity among Iranian EFL university students. Asian Journal of Social Sciences \& Humanities 1(4), 165-171.

Laufer, B., \& Goldstein, Z. (2004). Testing vocabulary knowledge: Size, strength, and computer adaptiveness. Language Learning, 54(3), 399-436. doi: https://doi.org/10.1111/j.00238333.2004.00260.x

Laufer, B., \& Nation, P. (1995). Vocabulary size and use: Lexical richness in L2 written production. Applied Linguistics, 16(3), 307-322. doi: 10.1093/applin/16.3.307

Levesque, K. C., Kieffer, M. J., \& Deacon, S. H. (2017). Morphological awareness and reading comprehension: Examining mediating factors. Journal of Experimental Child Psychology, 160, 1-20. doi: https://doi.org/10.1016/j.jecp.2017.02.015

Li, Y.-s., \& Chen, S.-h. (2016). Relative effectiveness of phonological and morphological awareness training on L2 word reading in EFL children. System, 60, 93-104. doi: https://doi.org/10.1016/j.system.2016.06.005

McCutchen, D. (2000). Knowledge, processing, and working memory: Implications for a theory of writing. Educational Psychologist, 35(1), 13-23. doi: https://doi.org/10.1207/S15326985EP3501_3

McCutchen, D., \& Logan, B. (2011). Inside incidental word learning: Children's strategic use of morphological information to infer word meanings. Reading Research Quarterly, 46(4), 334349. doi: 10.1002/RRQ.003

McCutchen, D., \& Stull, S. (2015). Morphological awareness and children's writing: Accuracy, error, and invention. Reading and Writing, 28(2), 271-289. doi: https://doi.org/10.1007/s11145-014-9524-1

McNamara, D. S., Crossley, S. A., \& McCarthy, P. M. (2009). Linguistic features of writing quality. Written Communication, 27(1), 57-86. doi: https://doi.org/10.1177/0741088309351547

Myhill, D. (2008). Towards a linguistic model of sentence development in writing. Language and Education, 22(5), 271-288. doi: doi.10.1080/09500780802152655

Nagy, W., \& Townsend, D. (2012). Words as tools: Learning academic vocabulary as language acquisition. Reading Research Quarterly, 47(1), 91-108. doi: 10.1002/RRQ.011

Nagy, W. E., \& Anderson, R. C. (1984). How many words are there in printed school English? Reading Research Quarterly, 19(3), 304-330.

Nation, I. S. (2001). Learning vocabulary in another language: Ernst Klett Sprachen.

Northey, M. (2013). Control of morphological forms in writing. University of Washington.

Pallant, J. (2005). SPSS survival manual: A step guide to data analysis using SPSS for Windows version 12: Chicago, Illinois: Open University Press.

Paltridge, B. (2002). Thesis and dissertation writing: An examination of published advice and actual practice. English for Specific Purposes, 21(2), 125-143. doi: https://doi.org/10.1016/S0889-4906(00)00025-9

Paltridge, B., \& Woodrow, L. (2012). Thesis and dissertation writing: Moving beyond the text. Academic writing in a second or foreign language, 88-104.

Ririn, K. (2010). Morphological error found in the English essays of the fifth semester students of English letters and language department of UIN Malang in 2008. Maulana Malik Ibrahim State Islamic University of Malang. 
Schleppegrell, M. J. (2012). Academic language in teaching and learning. The Elementary School Journal, 112(3), 409-418.

Shoeib, A. F. (2017). Morphological awareness and its association with reading comprehension of EFL Saudi University students. European Journal of English Language Teaching, 3(2), 52-77.

Singh, M. K. M. (2015). International graduate students' academic writing practices in Malaysia: Challenges and solutions. Journal of International Students, 5(1), 12-22.

Singson, M., Mahony, D., \& Mann, V. (2000). The relation between reading ability and morphological skills: Evidence from derivational suffixes. Reading and Writing, 12(3), 219252. doi: https://doi.org/10.1023/A:1008196330239

Sparks, E., \& Deacon, S. H. (2015). Morphological awareness and vocabulary acquisition: A longitudinal examination of their relationship in English-speaking children. Applied Psycholinguistics, 36(2), 299-321. doi: 10.1017/S0142716413000246

Stowe, M. (2019). Teaching morphology: Enhancing vocabulary development and reading comprehension: Retrieved from William and Mary School of Education https://education. wm ....

Sumarni, B. (2016). The relationship between morphological awareness and English vocabulary knowledge of sixth semester students in IKIP Mataram. Journal of English Language Teaching, 3(2), 67-74. doi: https://doi.org/10.33394/jo-elt.v3i2.2430

Tabatabaei, O., \& Yakhabi, M. (2011). The relationship between morphological awareness and vocabulary size of EFL learners. English Language Teaching, 4(4), 262-273. doi: $10.5539 /$ elt.v4n $4 \mathrm{p} 262$

Varatharajoo, C. (2016). The effectiveness of morphemic analysis instruction towards ESL students' vocabulary development. University of Malaya.

Wilson-Fowler, E. B., \& Apel, K. (2015). Influence of morphological awareness on college students' literacy skills: A path analytic approach. Journal of Literacy Research, 1-28. doi: DOI: $10.1177 / 1086296 \mathrm{X} 15619730$

Wolter, J. A., \& Green, L. (2013). Morphological awareness intervention in school-age children with language and literacy deficits: A case study. Topics in Language Disorders, 33(1), 27 41. doi: DOI: 10.1097/TLD.0b013e318280f5aa

Xue, J., \& Jiang, X. (2017). The developmental relationship between bilingual morphological awareness and reading for Chinese EFL adult learners: A longitudinal study. Reading and Writing, 30(2), 417-438. doi: https://doi.org/10.1007/s11145-016-9683-3

Yucel-Koc, M. (2015). The role of morphological awareness in academic vocabulary and reading comprehension skills of adult ESL learners. Seattle Pacific University.

Zhang, D., \& Koda, K. (2012). Contribution of morphological awareness and lexical inferencing ability to L2 vocabulary knowledge and reading comprehension among advanced EFL learners: Testing direct and indirect effects. Reading and Writing, 25(5), 1195-1216. doi: https://doi.org/10.1007/s11145-011-9313-z

Zhang, H. (2016). Concurrent and longitudinal effects of morphological awareness on reading comprehension among Chinese-speaking children. Reading Psychology, 37(6), 867-884. doi: DOI: $10.1080 / 02702711.2015 .1133463$

\section{Copyrights}

Copyright for this article is retained by the author(s), with first publication rights granted to the Journal.

This is an open-access article distributed under the terms and conditions of the Creative Commons Attribution license (CC BY-NC-ND) (http://creativecommons.org/licenses/by-nc-nd/4.0/). 